\title{
APEL VERSUS HABERMAS: COMO DISSOLVER A ÉTICA DISCURSIVA PARA SALVAGUARDÁ-LA JURIDICAMENTE
}

\author{
Delamar José Volpato Dutra ${ }^{1}$ \\ djvdutra@yahoo.com.br
}

RESUMO $A$ relação entre direito e moral é a clef de voûte do problema da justificação do direito. De fato, a ocupação filosófica com a justificação do direito porta conexão com a moral, como, por exemplo, em Kant, Dworkin, Alexy, Rawls. Pretende-se apresentar o papel desempenhado pela ética discursiva na fundamentação do direito proposta por Habermas. Apesar de Habermas dispor de uma moral cognitivista e ter apresentado uma fundamentação para o princípio de universalização próprio para a mesma, tal princípio parece ter desaparecido do empreendimento tardio de fundamentação da correção jurídica. Tal acusação é endereçada a Habermas exemplarmente por Apel, Kettner e Heck. Pretende-se sustentar, no presente

1 Departamento de Filosofia da UFSC, CNPq. Recebido em 12/02/2009 e aprovado em 10/02/2010. Das abreviaturas

\begin{tabular}{|l|l|}
\hline FG & $\begin{array}{l}\text { HABERMAS, Jürgen. Faktizität und Geltung: Beiträge zur Diskurstheorie des Rechts und des } \\
\text { demokratischen Rechtsstaats. 4. Aufl. Frankfurt am Main: Suhrkamp, 1994. }\end{array}$ \\
\hline TrFG1 & $\begin{array}{l}\text { HABERMAS, Jürgen. Direito e democracia: entre faticidade e validade. [Trad. F. B. Siebeneichler: } \\
\text { Faktizität und Geltung: Beiträge zur Diskurstheorie des Rechts und des demokratischen } \\
\text { Rechtsstaats]. Rio de Janeiro: Tempo Brasileiro, 1997. v. 1. }\end{array}$ \\
\hline TrFG2 & $\begin{array}{l}\text { HABERMAS, Jürgen. Direito e democracia: entre faticidade e validade. [Trad. F. B. Siebeneichler: } \\
\text { Faktizität und Geltung: Beiträge zur Diskurstheorie des Rechts und des demokratischen } \\
\text { Rechtsstaats]. Rio de Janeiro: Tempo Brasileiro, 1997. [v. 2]. }\end{array}$ \\
\hline AA & $\begin{array}{l}\text { As referências a Kant são feitas tomando como base a paginação da edição da academia, } \\
\text { abreviada por AA, seguidas do número do volume, em caracteres romanos, e da página, em } \\
\text { caracteres arábicos. As citações literais são feitas a partir das traduções para o vernáculo das } \\
\text { referidas obras. }\end{array}$ \\
\hline
\end{tabular}

KRITERION, Belo Horizonte, nº 121, Jun./2010, p. 103-116. 
trabalho, especialmente contra Apel, que a moral discursiva não desaparece do empreendimento de fundamentação do direito, sendo apenas redefinido o papel que ela desempenha nesta tarefa, embora em um sentido mais forte do que Habermas pretende reconhecer. De fato, Habermas parece atribuir à moral um papel negativo na justificação do direito. Pretende-se defender que os direitos morais não cumprem uma função somente negativa no procedimento de justificação do direito, por mais importante que seja tal função assim concebida, seja porque tais direitos passam, de alguma forma, a compor a forma jurídica e mesmo os direitos básicos, seja porque a própria tese da complementaridade parece exigir que o direito positive a moral.

Palavras-Chave Habermas, Apel, Filosofia do direito, Moral, Direito

ABSTRACT The connections between the law and morality are the clef de voûte of law justifying problem. The philosophic preoccupation with those connections is well exemplified in the works of Kant, Dworkin, Alexy, Rawls. This paper aims to show the role discursive ethics plays in the foundation of the law, according to Habermas' perspective. Although Habermas had established a cognitivist morality and shown an argument for the principle of universalization, it seemed to have disappeared form his later intent of juridical correction foundation. This accusation, addressed to Habermas, was equally supported by Apel, Kettner and Heck. This article intends, especially against Apel's point of view, to demonstrate that discursive morality did not disappear, but have just traversed a period of conceptual modifications. Indeed, for Habermas, morality seems to play a negative role in the law justification process. Despite this underestimation of morality, the paper defends the relevance of moral rights for this process, which increases, even more, the importance of the connections between the law and morality in the discussion of Habermas' complementarity thesis.

Keywords Habermas, Apel, Legal Philosophy, Morality, The law

Habermas, no prefácio a FG, ao mencionar a reformulação de sua própria teoria concernente ao tema da complementaridade entre direito e moral se refere à posição de Apel, do que se pode concluir que o estudo das divergências entre ambos é um bom método para poder tornar mais clara a própria posição defendida por Habermas em FG. Por isso, utilizar-se-ão as discordâncias de 
Apel em relação a Habermas como uma matriz daquilo que o autor de FG está provavelmente recusando como sendo a maneira correta de entender a mencionada complementaridade.

A discordância principal de Apel com relação a Habermas reside na neutralização moral do princípio do discurso operada em FG, o que teria levado a uma dissolução [Auflösung] da ética discursiva. Desta tese da neutralidade se seguem consequências das quais Apel discorda. A primeira delas pode ser vislumbrada na acusação feita de que, assim concebida a arquitetônica de FG, um dos intentos principais de Habermas, a saber, fundamentar o direito, resultaria contraditório. A segunda consequência é vislumbrada na acusação de que o próprio empreendimento da ética discursiva visando à fundamentação do princípio de universalização se tornaria impossível.

A primeira acusação pode ser encontrada no texto Auseinandersetzungen in Erprobung des transzendentalpragmatischen Ansatzes ${ }^{2}$ de 1998. Segundo Apel, Habermas pretende encontrar a base normativa do direito em um princípio do discurso moralmente neutro, mas, ao mesmo tempo, sustenta haver uma dependência da validade normativa do direito em relação à moral, ${ }^{3}$ visto Habermas sustentar que "o sentido universalista do princípio do direito" requer "um ponto de vista genuinamente moral". ${ }^{4}$ Nesse sentido, não é clara a conexão entre o sistema de direitos básicos e os direitos morais. Isso sem contar a tese de que o direito deve estar em harmonia com a moral. Esses pontos deverão se tornar mais claros a seguir.

A segunda objeção pode ser encontrada no texto "Regarding the relationship of morality, law and democracy: on Habermas's Philosophy of Law (1992) from a transcendental-pragmatic point of view". ${ }^{5}$ Para Apel, se Habermas partir da formulação dada ao princípio do discurso em $\mathrm{FG}$, ele não poderá deduzir o princípio de universalização, porque aquele é neutralizado moralmente. ${ }^{6}$

No seu texto, Apel menciona, por duas vezes, a nota 4 do prefácio a FG. Na primeira menção ele afirma: "a minha tentativa de uma fundamentação do Direito, como implicação da parte $B$ da ética do discurso, foi refutada por Habermas

2 APEL, Karl-Otto. Auseinandersetzungen in Erprobung des transzendentalpragmatischen Ansatzes. Frankfurt am Main: Suhrkamp, 1998. Tal problema se encontra no cap. 13 do referido texto, cujo título é "Auflösung der Diskursethik? Zur Architektonik der Diskursdifferenzierung in Habermas' Faktizität und Geltung. Dritter, transzendentalpragmatisch orientierter Versuch, mit Habermas gegen Habermas zu denken". Este capítulo foi traduzido por Luiz Moreira e publicado no livro APEL; OLIVEIRA; MOREIRA, 2004, p. 201-321. Será usada a mencionada tradução para o vernáculo com a indicação da página da edição original. APEL, 1998, p. 734-735.

4 TrFG1, p. 137 [FG, p. 132-133].

5 APEL(1992), 2002, p. 22.

6 No texto a seguir há uma tentativa de provar que tal é possível: VOLPATO DUTRA, 2002. 
em Direito e democracia: entre faticidade e validade, na críptica nota 4". ${ }^{7}$ No contexto desta passagem, Apel é simpático, embora com reservas, à posição de Habermas nas Tanner Lectures. A sua ressalva tem conexão com a segunda menção que faz à referida nota 4 . Nessa alusão posterior, Apel se reporta à seguinte afirmação de Habermas: "tentarei clarificar as determinações formais do direito, lançando mão da relação complementar entre direito e moral. Esta clarificação é parte integrante de uma explicação funcional, não de uma fundamentação normativa do direito. Pois a forma jurídica não é um princípio que possa ser 'fundamentado' epistêmica ou normativamente". ${ }^{8}$ Assim se pronuncia Apel:

aparentemente esta explicação um tanto repentina e abrupta guarda relação mais estreita com a minha exigência expressa de uma fundamentação normativa, e não só com a exigência de uma explicação funcional, da forma específica das normas jurídicas exigíveis por meio da coação estatal [...] Na nota de rodapé 4 (da "Introdução") de Direito e democracia, Habermas afastou esta minha exigência e, com ela, simultaneamente também, imagino, a sua própria posição anterior nas Tanner Lectures de 1986, como "abordagem normativa" do problema da relação entre Moral e Direito. No entanto, a minha irritação, no contexto atual do problema, não reside no rechaço (pretendido também, imagino, na nota de rodapé) de uma fundamentação moral da forma específica das normas jurídicas como normas de coerção (que, entretanto, considero necessária), mas no rechaço - que, ao que parece, vai além disso — de qualquer "fundamentação normativa" da "forma jurídica".

A correta interpretação da afirmação da nota 4 depende da correta interpretação das Tanner Lectures, principalmente. Nesse ponto, Apel, por querer fundamentar normativamente a própria forma jurídica, interpreta equivocadamente as Tanner Lectures. Na verdade, a abordagem normativa das Tanner Lectures que é revisada em FG é outra e não aquela denotada por Apel. Ao que parece Habermas nunca pensou em uma justificação moral da forma jurídica, nem no contexto das Tanner Lectures. Tal rechaço parece ser uma constante em sua obra. O ponto de Habermas é que "a pretensão de validade deontológica de mandamentos morais seria relativizada e ligada a condições de sucesso do agir estratégico [...] caso o cuidado 'político' em sentido amplo para com o 'sucesso aproximativo do elemento moral em geral' (na figura de um outro princípio da responsabilidade ética, por exemplo) fosse incorporado à própria moral". ${ }^{10}$ Para ele, a política não se deixa moralizar diretamente, de tal forma que o único caminho aberto para uma reforma moral do nosso comportamento, ou melhor, para a civilização das condições de vida 
é o da domesticação do poder via juridificação controlada democraticamente, o que denota grande confiança no direito e mais ainda na democracia.

Outro ponto importante destacado por Apel se relaciona à definição do princípio do discurso. Ele observa, corretamente, que o "princípio do discurso pode e precisa ser formulado de modo tão neutro que nem sequer se mencionaria que nele haveria 'normas de ação' a serem fundamentadas; é que o princípio do discurso compõe também a base do discurso de formação do consenso, referente à verdade, da filosofia teórica". ${ }^{11}$ De fato, Habermas apresenta uma formulação do princípio do discurso que parece excluir sua aplicação às proposições teóricas, já que a formulação dada opera no âmbito da razão prática - "D: são válidas todas as normas de ação às quais todos os possíveis atingidos poderiam dar o seu assentimento, na qualidade de participantes de discursos racionais" ${ }^{12}$ —, embora não seja difícil encontrar formulações mais gerais do mesmo, como a seguinte: 'sob a rubrica 'discurso' introduzo a forma de comunicação caracterizada pela argumentação, na qual se tornam tema as pretensões de validade que se tornaram problemáticas e se examina se são legítimas ou não". ${ }^{13}$ No entanto, o que é importante, para Habermas, é a independência do princípio do discurso em relação à moral, seja em qual formulação for, ao contrário de Apel, para quem "o princípio do discurso não é 'moralmente neutro'; ele pressupõe o reconhecimento da igualdade de direitos". ${ }^{14}$ Na verdade, a tese de Apel é que o princípio do discurso não só inclui o princípio de universalização da ética discursiva como também uma justificação da própria forma jurídica. Ele afirma: "parto da premissa de que o princípio do discurso — que, no modo de pensar, é irrecorrível — de fato já inclui, como conteúdo, o princípio moral primordial, e de que esse princípio moral, por sua vez, não só contém o princípio ' $U$ ' [...] mas, além disso, também um princípio de responsabilidade", ${ }^{15}$ sendo que este último daria uma justificação normativa para a própria forma jurídica. Dito claramente, "o princípio moral primordial, do qual a pragmática transcendental toma o seu ponto de partida como ética do discurso, é, a bem da verdade, uma pressuposição necessária de qualquer ato sério de argumentação, mas não é uma mera 'regra de argumentação"”. ${ }^{16}$

Com relação a esse particular, o problema geral de Apel é confundir regras lógicas com conteúdos morais: "as tentativas feitas, até agora, para fundamentar uma ética discursiva, padecem do fato de que as regras da argumentação 
são curto-circuitadas com conteúdos e pressupostos da argumentação - e confundidas com princípios morais enquanto princípios da ética filosófica". ${ }^{17}$ Isso é um ataque frontal à formulação de Apel de que a lógica pressupõe uma ética. De fato, Apel afirma: "neste sentido também não se pode dizer que a lógica implica numa ética. Pode-se afirmar, no entanto, que a lógica - e com ela também todas as ciências e tecnologias - pressupõe uma ética como sua condição de possibilidade". ${ }^{18} \mathrm{Na}$ verdade, o ponto é que se trata de duas ordens categorialmente distintas. Ou seja, é preciso distinguir a normatividade no sentido transcendental da normatividade no sentido deontológico. ${ }^{19}$ Quiçá, um dos possíveis motivos da confusão de Apel ocorra em razão — faute de mieux — da linguagem jurídica usada para descrever as condições de possibilidade do discurso ou da comunidade ideal de comunicação, fazendo com que seja sugerida uma leitura ética do que deveria ser uma condição de possibilidade lógica - embora pragmática - da racionalidade comunicativa.

Um outro aspecto importante do texto de Apel é apontar para o que parece ser um verdadeiro problema em Habermas. Apel, tendo em vista a afirmação contida em FG, a saber,

ele [Rousseau] não pode explicar a possibilidade de uma mediação entre a requerida orientação pelo bem comum dos cidadãos e os interesses sociais diferenciados das pessoas privadas, ou melhor, não sabe dizer como é possível mediar, sem repressão, entre a vontade comum, construída normativamente, e o arbítrio dos sujeitos singulares. Para que isso acontecesse, seria preciso um ponto de vista genuinamente moral, a partir do qual poderia ser avaliado se o que é bom para nós é do interesse simétrico de cada um. No final da versão ética do conceito de soberania popular [que Habermas imputa a Rousseau], perde-se o sentido universalista do princípio do direito, ${ }^{20}$

sustenta a proposição de que o próprio Habermas permaneceu caudatário da tese de uma relação positiva da moral na determinação da justificação do direito, pois, como conciliar a afirmação contida na citação "seria preciso um ponto de vista genuinamente moral", somada à afirmação segundo a qual "uma ordem jurídica só pode ser legítima, quando não contrariar princípios morais", ${ }^{21}$ com a tese da neutralidade? Sugere-se, neste estudo, um modo de

17 HABERMAS, 1989, p. 116-117.

18 APEL, 1994, p. 119. O texto foi originalmente publicado no livro Transformation der Philosophie.

19 "Quando nós, na base de uma distinção entre sentido transcendental e sentido deontológico de normatividade, entendemos que o potencial de racionalidade insertado de modo geral em discursos não é obrigatório em sentido deontológico, é possível interpretar o juízo imparcial sobre a consensualidade de normas, exigido de modo não-específico por ' $D$ ', como algo que ainda é 'neutro do ponto de vista da moral e do direito'" [HABERMAS, 2007, p. 104; HABERMAS, 2005, p. 96].

20 TrFG1, p. 137 [FG, p. 132-3]. Citado por Apel à p. 826 de seu texto Auseinandersetzungen in Erprobung des transzendentalpragmatischen Ansatzes.

21 TrFG1, p. 140-1 [FG, p. 137]. 
ler o texto que permite admitir "um ponto de vista genuinamente moral", sem que com isso seja necessário abandonar a tese da neutralidade ou subordinar completamente, sob o ponto de vista normativo, o direito à moral. $\mathrm{O}$ que a construção de Habermas parece excluir são formulações como a de Kant, que sustentam o seguinte conjunto de teses:

- tese da subsunção do direito à moral. De fato, Kant sustenta que "a doutrina do direito e a doutrina da virtude se distinguem, então, bem menos por deveres diferentes que pela diferença de legislação que associa à lei um móbil antes que um outro". ${ }^{22}$ Ademais, ele faz afirmações como as seguintes: (a) "o conceito do direito, enquanto relacionado a uma obrigação correspondente (i. e., seu conceito moral), diz respeito [...]",23 (b) "o direito como faculdade (moral) de obrigar outros, i. e., como um fundamento legal para os últimos (titulum), tem por divisão superior aquela entre direito inato e adquirido". ${ }^{24}$ Guido de Almeida chega a sustentar que para Kant as leis jurídicas são uma subclasse das leis morais. ${ }^{25}$ No mesmo diapasão Heck conclui: "deveres de direito não passam, para Kant, de uma subclasse da categoria dos deveres morais". ${ }^{26}$

- tese do conhecimento moral da liberdade: "mas por que a doutrina dos costumes (moral) é ordinariamente (particularmente por Cícero) intitulada a doutrina dos deveres e não também dos direitos, dado que uns se referem aos outros? - O fundamento é este: Nós só conhecemos nossa própria liberdade (de que procedem todas as leis morais, portanto também todos os direitos tanto quanto os deveres) através do imperativo moral, que é uma proposição que ordena um dever, a partir do qual pode ser desenvolvida posteriormente a faculdade de obrigar os outros, i. e., o conceito do direito". ${ }^{27}$

A tese da subsunção Habermas a critica pelo seu viés platônico, ou seja, "subjaz a essa construção a ideia platônica segundo a qual a ordem jurídica copia e, ao mesmo tempo, concretiza no mundo fenomenal a ordem inteligível

25 ALMEIDA, 2006, p. 209-222 passim. Wood sustenta uma posição diferente. Para ele: "Kant coloca o 'direito' à frente da 'ética', na sua exposição, para enfatizar que as duas partes são distintas e que deveres de direito não são meramente uma subclasse de deveres éticos, da mesma forma que $D$ não pode ser derivado da FA, da FH, ou da FLU ou qualquer outra formulação do princípio da moralidade" [WOOD, 2005 , p. 145]. Wood chega mesmo a sustentar que o princípio universal do direito não é um padrão moral, mas um padrão puramente jurídico de permissibilidade, implicando que "ações corretas, nesse sentido, incluem somente ações que, de acordo com os padrões fundados pelo princípio $D$, não podem ser coercitivamente obstados, mesmo se forem contrários a deveres morais" [WOOD, 2005, p. 144]. Uma razão que ele parece apontar para isso é que o princípio do direito "produz uma similaridade verbal superficial com a FLU, mas a diferença entre este e todas as formas do princípio da moralidade são muito mais significantes do que as similaridades" [WOOD, 2005, p. 144].

26 HECK, 2000, p. 61.

27 AA VI 239. 
de um 'reino dos fins"”. ${ }^{28}$ Com relação à segunda tese, Habermas propugna um autêntico conhecimento jurídico da liberdade e não um conhecimento moral.

Pretende-se argumentar no sentido de demonstrar que a filosofia do direito de Habermas se situa entre o caminho da completa subordinação normativa do direito à moral seguido por Kant e Apel e o caminho decisionista da completa separação seguido por Weber e Kelsen, de tal forma que o legislador mantenha sua autonomia, sem, contudo, poder contrariar normas morais. Portanto, é possível uma via intermediária que conecta a normatividade moral e a jurídica, sem que esta última seja reduzida à primeira. Nesse sentido, ele afirma no posfácio a FG que "a nau da teoria do discurso navega entre os escolhos do direito natural e do positivismo jurídico". ${ }^{29}$

Assim, se o princípio do discurso coincidisse com o princípio de universalização, então, "o princípio moral, oculto no princípio do discurso, passaria a ser novamente a única fonte de legitimação para o direito". ${ }^{30}$ Ainda que para Habermas os direitos humanos possam ser fundamentados como direitos morais, ${ }^{31}$ um dos pontos interessantes de sua obra é o de conseguir basear parte dos direitos humanos independentemente da moral, justamente partindo da análise das características formais do direito, de tal forma que o código do direito já "implica, ao mesmo tempo, a garantia de liberdades subjetivas". ${ }^{32}$ Ora, justamente as liberdades subjetivas são o coração de parte dos direitos humanos, ${ }^{33}$ sendo, quiçá, sua parte fundamental. O princípio do discurso, por sua vez, tem a função de dar conta de uma repartição igualitária desses direitos subjetivos, mormente por meio do procedimento democrático. É só assim que os direitos humanos não são impostos ao legislador de forma paternalista.

$\mathrm{O}$ que se poderia aduzir como possíveis razões que Habermas parece apontar para a defesa da tese da neutralidade avançada acima, como (1) a indeterminação dos princípios morais, carentes de um significado semântico melhor definido, e (2) a recusa do paternalismo moral com relação ao legislador

28 TrFG1, p. 140 [FG, p. 136]. Embora esteja suficientemente claro o sentido do termo platonismo aqui usado, ou seja, como hierarquia de normas, é necessário, porém, esclarecer que o ajuizamento da ética kantiana como um certo platonismo de forma alguma implica uma concepção substancial do bem, até porque Habermas tende a interpretar Kant, na linha de Rawls, como um processualista.

29 TrFG2, p. 313-4 [FG, p. 668]. Posfácio.

$30 \operatorname{TrFG2,~p.~} 321$ [FG, p. 676].

31 FG, p. 670. Nesse sentido, Maria Clara Dias sustenta que os direitos básicos são princípios morais, imputando a sua satisfação como uma condição de possibilidade da democracia [DIAS, Maria Clara. O que pode a ética na política: considerações acerca do conceito de democracia. In: HECK; BRITO, 1997, p. 291].

$32 \operatorname{TrFG}$, p. 316 [FG, p. 671].

33 A formulação kantiana do direito à liberdade parece atender a este requisito de ser um direito subjetivo, já que ela é definida como a faculdade de buscar a felicidade a seu próprio modo: "ninguém me pode constranger a ser feliz à sua maneira (como ele concebe o bem-estar dos outros homens), mas a cada um é permitido buscar a sua felicidade pela via que lhe parecer boa" [AA VIII 290]. 
político, parecem não ser motivos suficientes. Com relação ao ponto da indeterminação, Habermas - vale mencionar - , embora afirme em FG que, sob o ponto de vista conceitual, o princípio da moral e o princípio da democracia se expliquem reciprocamente, ${ }^{34}$ oblitera discretamente a positivação de princípios morais importantes e olha com certa desconfiança posições como a de Dworkin, por agudizarem a problemática da indeterminação do direito, ${ }^{35}$ pois dão eficácia plena a tais princípios, ainda que vagos no seu conteúdo. $\mathrm{O}$ próprio Habermas, com relação a este último ponto, não descarta os princípios morais mais importantes. Tanto é verdade que os mesmos, ou algo bem semelhante a eles, são alavancados como compondo o próprio código do direito e, portanto, como condição de possibilidade da própria formulação jurídica da democracia. Ou seja, os princípios morais mais importantes parecem ser elevados a princípios possibilitadores da ordem jurídica enquanto tal. De fato, liberdade privada e liberdade pública são pensadas como cooriginárias. Ainda que Habermas desafie a conotação moral de tais direitos, buscando conferirlhes uma estirpe estritamente jurídica, ecoam pelo seu texto as semelhanças entre liberdade privada e direitos humanos ou direitos morais.

Veja-se que o próprio Habermas afirma que a complementaridade do direito, mesmo ao modo da neutralidade, não implica uma neutralidade moral do mesmo, justamente a acusação que Apel e outros parecem endereçar à nova posição em FG. Eis o que sustenta o autor de FG: "a relação complementar, no entanto, não significa uma neutralidade moral do direito". ${ }^{36}$ Tal caráter complementar não significa que o direito seja moralmente neutro, pois a moral adentra no processo legislativo e o direito não pode contrariar a moral. ${ }^{37} \mathrm{Ou}$ seja, Habermas dilui a ética discursiva no interior do direito, seja no sistema de direitos, seja pelo caráter permeável do procedimento democrático que permite a livre circulação dos argumentos morais - embora não possa obrigar a tal —, seja na interdição dos produtos do procedimento democrático contrariar princípios morais. Sem contar que o direito é chamado a suprir os déficits cognitivos e institucionais da moral. O ponto é que a correção jurídica não se identifica mais à correção moral. ${ }^{38}$ No entanto, será que Apel chega a ponto da identificação? Se procedesse assim, como poderiam ser regradas as matérias carentes de consenso moral, como o aborto, a eutanásia, a clonagem?

34 "Begrifflich erläutern sich Moral - und Demokratieprinzip wechselseitig" [FG, p. 123].

35 "Em todos os níveis de jurisprudência [Rechtsprechung], entram em jogo princípios que envolvem uma interpretação construtiva do caso particular, no sentido de Dworkin" [TrFG1, p. 303] [FG, p. 298].

36 TrFG2, p. 313 [FG, p. 667]. Posfácio.

37 FG, p. 667-8. Nachwort.

38 FG, p. 677. Nachwort. 
A plausibilidade desta interpretação que dilui a ética discursiva para melhor preservá-la pode ser vislumbrada no modelo do processo da formação política racional da vontade apresentado a seguir. Nele, parece estar claro o papel de destaque que a moral desempenha, uma função mais importante seja do que o próprio Habermas parece explicitamente sustentar ao longo do texto, posto atribuir a ela apenas uma função negativa, seja do que os seus intérpretes o acusam. Pelo esquema a seguir, todos os argumentos têm que passar pelo "ffiltro" do discurso moral. Ou seja, "para que o princípio do discurso seja levado em conta por todos sem exceção, é preciso supor a combinalidade [Vereinbarkeit] de todos os programas negociados ou obtidos discursivamente com aquilo que pode ser justificado moralmente". ${ }^{39}$ Mas como operaria tal discurso? Ele só reteria o que com ele fosse incompatível, operando negativamente? Ele faria exigências de positivação, já que Habermas fala de transferências segundo o esquema a seguir? ${ }^{40}$ Tais pontos são importantes, inclusive tendo em vista a argumentação de que o direito depende de fontes de legitimidade que ele não tem à sua disposição. ${ }^{41}$

\section{Ein Prozeßmodell der vernünftigen politischen Willensbildung}

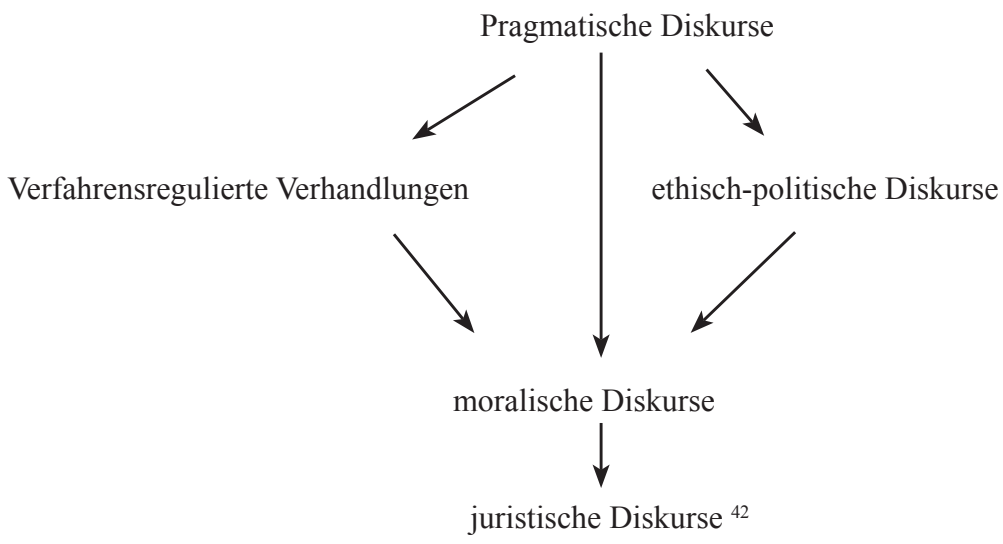

39 TrFG1, p. 209 [FG, p. 206-207].

40 FG, p. 207.

41 "A compreensão discursiva do sistema dos direitos conduz o olhar para dois lados: de um lado a carga da legitimação da normatização jurídica das qualificações dos cidadãos desloca-se para os procedimentos da formação discursiva da opinião e da vontade, institucionalizados juridicamente. De outro lado, a juridificação da liberdade comunicativa significa também que o direito é levado a explorar fontes de legitimidade das quais ele não pode dispor" [TrFG1, p. 168]. "Andererseits bedeutet die Verrechtlichung der kommunikativen Freiheit auch, daß sich das Recht Quellen der Legitimation erschließen muß, über die es nicht verfügen kann" [FG, p. 165].

42 FG, p. 207. 
Cabe mencionar que a interpretação avançada — qual seja, a de que em FG Habermas vincula de alguma forma os conteúdos resultantes do procedimento moral e do procedimento jurídico, cuja base se encontra na sua afirmação, já exposta acima, de que uma ordem jurídica não pode contrariar princípios morais - encontra nesse modelo do processo da formação política racional da vontade também uma dificuldade, pois nele se sugere que uma matéria sobre a qual o legislador deve se pronunciar passaria, primeiro, pelo crivo dos discursos de negociação, pragmático e ético-político; em seguida, passaria pelo crivo do discurso moral para, então, provada a sua compatibilidade com argumentos morais, adentrar no discurso jurídico. Tal dificuldade pode configurar uma outra hipótese interpretativa, segundo a qual haveria uma sucessão de procedimentos pelos quais a matéria carente de juridicização deveria passar, sendo um deles o moral, no qual apenas se avaliaria sua compatibilidade ou não com uma argumentação moral, sendo os argumentos decisivos para sua legitimação avançados pelos outros discursos. O problema dessa hipótese é que ela só parece encontrar guarida na apresentação do próprio modelo, sendo que as demais menções à questão sugerem uma formulação mais substantiva que esta.

Outrossim, o modelo poderia querer apenas sugerir como o controle da moralidade do direito poderia operar, ou seja, processualmente, através do próprio discurso moral, e não solitária ou monologicamente. Mesmo essa formulação parece contrariar outras segundo as quais o processo jurídico faria uma combinatória de argumentos, como a que segue: "a relação complementar, no entanto, não significa uma neutralidade moral do direito. Pois o processo legislativo permite que razões morais fluam para o direito. E a política e o direito têm que estar afinados [Einklang] com a moral". ${ }^{43}$ Tal afirmação não parece albergar a interpretação de uma sucessão de procedimentos. Ademais, a própria ideia de complementaridade explicitamente sustentada por Habermas sugere uma relação entre direito e moral menos entrelaçada processualmente e mais mesclada funcionalmente, ainda que sob o ponto de vista do observador. ${ }^{44}$

43 TrFG2, p. 313 [FG, p. 667-8]. Posfácio. Na citação a seguir também parece haver uma concomitância da argumentação, antes que uma sucessão, ao menos nas três argumentações principais: "a formação política da opinião e da vontade, ultrapassando o nível pragmático, onde se procura saber o que podemos fazer em função de tarefas concretas, precisa esclarecer, em primeira linha, três questões, a saber: a que subjaz à formação de compromissos, onde se discute a possibilidade de harmonizar entre si preferências concorrentes; a questão ético-política acerca de nossa identidade pessoal e dos ideais que acalentamos realmente; e a questão prático-moral que nos leva a inquirir sobre o modo de agir para sermos justos" [TrFG1, p. 225] [FG, p. 222].

$44 \operatorname{TrFG} 2$, p. 313 [FG, p. 667-8]. Posfácio. 
Seja como for, o entrelaçamento entre direito e moral é enfraquecido em FG, melhor dito, ele será entendido de forma diferente, pois não se tratará mais de atar o procedimento jurídico ao moral, mas justamente de diferenciá-los. De sorte que a moral, neste texto, não pairará sobre o ordenamento jurídico como uma camada superior, mas emigrará para o direito sem, no entanto, implicar na perda da identidade deste último. A tese aqui sustentada é a de que, como contraponto a essa diferenciação, será forçada uma nova união ou novo entrelaçamento entre os produtos que resultam dos respectivos procedimentos, embora nada impeça que argumentos morais possam aflorar já diretamente no próprio nível do discurso jurídico de legislação.

Finalmente, então, as objeções de Habermas contra o fundamentalismo da posição de Apel podem ser assim compreendidas: (a) Apel visaria a fundamentar diretamente normas morais básicas sem passar pelo crivo discursivo da fundamentação de um princípio de universalização, ${ }^{45}$ visto que o conteúdo normativo das pressuposições gerais da argumentação possuiria um sentido deontologicamente obrigatório, ou seja, seria hábil a fornecer elementos concretos para uma inferência direta da reciprocidade e da igualdade de direitos exigidas fora da prática da argumentação. Habermas, por seu turno, nega ser possível extrair da substância normativa das pressuposições gerais da argumentação algo para exigências deontológicas concernentes à ação. ${ }^{46}$ Ou seja, "no final das contas, Apel confia, apesar de tudo, nas evidências infalíveis de um acesso direto, pré-analítico, às intuições de um participante da argumentação, já treinado na reflexão". ${ }^{47}$ Ademais, (b) Apel pretenderia "complementar a moral por meio de uma obrigação para a realização histórica da moral (ética da responsabilidade)". ${ }^{48}$

Tais críticas ao fundamentalismo de Apel, a saber, (a) à tese do caráter moral do conteúdo normativo das pressuposições gerais da argumentação que daria um acesso privilegiado à normatividade deontológica e (b) à tese da ética da responsabilidade que torna uma obrigação existencial realizar juridicamente a moral, constituem-se, portanto, em pontos de partida para se poder avançar uma compreensão melhor de como se deve compreender a relação entre a moral e o direito, discursivamente concebidos. 


\section{Referências}

ALMEIDA, Guido Antônio de. Sobre o princípio e a lei universal do Direito em Kant. Kriterion, Belo Horizonte, n. 114, p. 209-222, 2006.

APEL, Karl-Otto; OLIVEIRA, Manfredo Araújo de; MOREIRA, Luiz. Com Habermas, contra Habermas: direito, discurso e democracia. São Paulo: Landy, 2004. p. 201-321.

APEL, Karl-Otto. Auseinandersetzungen in Erprobung des transzendentalpragmatischen Ansatzes. Frankfurt am Main: Suhrkamp, 1998.

APEL, Karl-Otto. O a priori da comunidade de comunicação e os fundamentos da ética: o problema de uma fundamentação racional da ética na era da ciência. In: APEL, Karl-Otto. Estudos de moral moderna. Petrópolis: Vozes, 1994.

APEL, Karl-Otto. Regarding the relationship of morality, law and democracy: on Habermas's Philosophy of Law (1992) from a transcendental-pragmatic point of view. In: ABOULAFIA, Mitchell; BOOKMAN, Mayra; KEMP, Catherine. Habermas and Pragmatism. London; New York: Routledge, 2002.

AUSTIN, John. Lectures on Jurisprudence. Glashütten im Taunus: Auvermann, 1972. [v. 1]. (1. ed., 1863).

DIAS, Maria Clara. O que pode a ética na política: considerações acerca do conceito de democracia. In: HECK, José Nicolau; BRITO, Adriano Naves de. Ética e política. Goiânia: Ed. UFG, 1997.

DWORKIN, Ronald. Taking Rights Seriously. London: Duckworth, 1977.

HABERMAS, Jürgen. Consciência moral e agir comunicativo. Trad. Guido A. de Almeida: Moralbewusstsein und kommunikatives Handeln. Rio de Janeiro: Tempo Brasileiro, 1989.

HABERMAS, Jürgen. Direito e democracia: entre faticidade e validade. Rio de Janeiro: Tempo Brasileiro, 1997. [v. 1 e v. 2].

HABERMAS, Jürgen. Entre naturalismo e religião: estudos filosóficos. Rio de Janeiro: Tempo Brasileiro, 2007.

HABERMAS, Jürgen. Faktizität und Geltung: Beiträge zur Diskurstheorie des Rechts und des demokratischen Rechtsstaats. 4. Aufl. Frankfurt am Main: Suhrkamp, 1994. HABERMAS, Jürgen. Teoria y práxis. Madrid: Tecnos, 1987.

HABERMAS, Jürgen. Theorie des kommunicativen Handelns. Frankfurt am Main: Suhrkamp, 1981. Band 1.

HABERMAS, Jürgen. Vorstudien und Ergänzungen zur Theorie des kommunikativen Handelns. Frankfurt am Main: Suhrkamp, 1984.

HABERMAS, Jürgen. Zwischen Naturalismus und Religion: philosophische Aufsätze. Frankfurt am Main: Suhrkamp, 2005.

HECK, José N. Direito e moral: duas lições sobre Kant. Goiânia: EDUFG/EDUCG, 2000.

HECK, José N. Razão prática: uma questão de palavras?: A controvérsia Habermas/ Kant sobre moral e direito. Kant e-prints, Campinas, v. 1, n. 1, p. 19-30, 2006. 
KANT, I. Kants Werk: Akademie Textausgabe. Berlin; New York: Gruyter, 19671968.

KELSEN, Hans. Teoria geral do direito e do Estado. São Paulo: Martins Fontes, 2000.

KELSEN, Hans. Teoria pura do direito. [J. B. Machado: Reine Rechtslehre]. 3. ed. São Paulo: Martins Fontes, 1991.

KETTNER, Matthias. The Disappearance of Discourse Ethics in Habermas's Between Facts and Norms. In: BAYNES, Kenneth; SCHOMBERG, René von. Essays on Habermas's "Between Facts and Norms". Albany: SUNY, 2002. p. 201-218.

LUHMANN, Niklas. Sociologia do direito I. Rio de Janeiro: Tempo Brasileiro, 1983. [G. Bayer: Rechtssociologie 1].

MUGUERZA, Javier. Prólogo. In: VELASCO ARROYO, Juan Carlos. La teoría discursiva del derecho: sistema jurídico y democracia en Habermas. Madrid: Centro de Estudios Políticos y Constitucionales, 2000.

NOBRE, M. A idéia da teoria crítica. In: MÜLLER, Maria Cristina; CENCI, Elve Miguel. Ética, política e linguagem: confluências. Londrina: CEFIL, 2004.

NOBRE, Marcos. A teoria crítica. Rio de Janeiro: Zahar, 2004. p. 57-58.

RAWLS, John. A Theory of Justice. Revised Edition. Oxford: Oxford University Press, 1999.

RAWLS, John. Justiça como eqüidade: uma reformulação. São Paulo: Martins Fontes, 2003.

RAWLS, John. Political Liberalism. New York: Columbia University Press, 1996.

REGH, Wiliam. Translator's Introduction. In: HABERMAS, J. Between Facts and Norms: Contributions to a Discourse Theory of Law and Democracy. Trad. W. Rehg: Faktizität und Geltung: Beiträge zur Diskurstheorie des Rechts und des demokratischen Rechtsstaats. Cambridge: Polity Press, 1996.

VOLPATO DUTRA, Delamar José. Kant e Habermas: a reformulação discursiva da moral kantiana. Porto Alegre: EDIPUCRS, 2002.

VOLPATO DUTRA, Delamar José. O acesso comunicativo ao ponto de vista moral. Sintese Nova Fase, v. 25, n. 83, p. 509-526, 1998.

VOLPATO DUTRA, Delamar José; LOIS, C. C. Modelos de moralização do direito: um estudo a partir de Habermas. Seqüencia, v. 55, p. 233-252, 2007.

WEBER, Max. Os três tipos puros de dominação legítima. 5. ed. São Paulo: Ática, 1991. (Coleção grandes cientistas sociais, n. 13. WEBER, Max. Sociologia).

WEBER, Max. Wirtschaft und Gesellschaft. Tübingen: Mohr, [19--]. WOOD, Allen W. Kant. Oxford: Blackwell, 2005. 